\title{
Mesofauna assemblages on the extraradical mycelium of Pinus greggii roots with three ectomycorrhizal fungi
}

\section{Ensambles de mesofauna en el micelio extraradical de raíces de Pinus greggii con tres hongos ectomicorrízicos}

\author{
Irma Díaz-Aguilar ${ }^{1}$, Magdalena Martínez-Reyes ${ }^{1}$, Jesús Pérez-Moreno 1,2, Jorge Valdez-Carrasco ${ }^{3}$ \\ ${ }^{1}$ Colegio de Postgraduados, Posgrado en Edafología. Km. 36.5 carretera México-Texcoco, C.P. 56230, Montecillo, Estado de México, \\ México. \\ ${ }^{2}$ Kunming Institute of Botany, Chinese Academy of Sciences, Kunming, China. \\ ${ }^{3}$ Colegio de Postgraduados, Posgrado en Fitosanidad-Entomología y Acarología. Km. 36.5 carretera México-Texcoco, C.P. 56230, \\ Montecillo, Estado de México, México.
}

\section{RESUMEN}

Antecedentes: El micelio extraradical (MER) de hongos ectomicorrízicos es una red habitada por mesofauna del suelo, colémbolos y ácaros, formando interacciones durante el ciclo de vida del hongo, desde consumir hifas hasta dispersar esporas. Sin embargo, se desconoce si el MER podría influir en ensamblajes de la mesofauna.

Objetivos: Evaluar la abundancia y composición de las comunidades de mesofauna que habitan en el MER de Hebeloma mesophaeum, Laccaria laccata y Wilcoxina sp. en raíces de Pinus greggii.

Métodos: La mesofauna fue colectada en cepellones de P. greggii con 80 \% de colonización, utilizando un método de lavado.

Resultados y conclusiones: Se observó un efecto por las diferencias del MER sobre la riqueza y dominancia de especies, pero no sobre la abundancia y composición de las comunidades de mesofauna; Wilcoxina sp. presentó la menor riqueza de especies. Los colémbolos fungívoros formaron ensambles de especies de isotomidos-tullbergidos que habitan en el suelo. Los Entomobryidae e Hypogastruridae fueron las familias comunes sobre la superficie del suelo, éstas no fueron encontradas en Wilcoxina sp. Pocos ácaros depredadores (Mesostigmata y Endeostigmata) fueron encontrados. El micelio ectomicorrízico es un nicho trófico de la mesofauna y podría ser una fuerza evolutiva en estructurar la diversidad de especies.

Palabras clave: Acari, Collembola, hifas ectomicorrízicas, interacciones, microartrópodos edáficos

\section{ABSTRACT}

Background: The extraradical mycelium (ERM) of ectomycorrhizal fungi is a network inhabited by soil mesofauna, mainly collembolans and mites, forming interactions during the fungal life-cycle, from grazing on hyphae to spore dispersal. However, it is still unknown if ERM of ectomycorrhizal fungi could influence the structure of mesofauna assemblages.

Objective: To evaluate the abundance and community composition of the mesofauna inhabiting the ERM of Hebeloma mesophaeum, Laccaria laccata and Wilcoxina sp. in Pinus greggii roots.

Methods: Mesofauna was collected from the root balls of $P$. greggii with $80 \%$ of colonization using a washing method.

Results and conclusions: An effect was observed due to ERM differences on species richness and species dominance, but not an effect on the abundance and community composition of the mesofauna. However, Wilcoxina sp. presented the lowest species richness and diversity. Fungus-feeding collembolans shaped species-rich assemblages, being isotomid-tullbergid forms the soil-dwelling taxa. Entomobryidae and Hypogastruridae were the most common families on the soil surface, not being found in Wilcoxina sp., and only a few predatory mites of the Mesostigmata and Endeostigmata were found. The ectomycorrhizal mycelium constitutes a trophic niche of the mesofauna and it might be an evolutionary force in structuring species composition and diversity.

Keywords: Acari, Collembola, ectomycorrhizal hyphae, edaphic microarthropods, interactions

\section{ARTICLE HISTORY}

Received 18 November 2020 / Accepted 21 May 2021

On line 15 July 2021
CORRESPONDING AUTHOR

\ Irma Díaz-Aguilar, idiaz@colpos.mx, idiaz@alberta.ca

ORCID: 0000-0001-9803-8231 


\section{INTRODUCTION}

Ectomycorrhizal symbiosis is one of the most important mutualistic relationships established by forest tree roots and fungi (Smith and Read 2008). The extraradical mycelium (ERM) is the part more closely in contact with the soil (Leake et al. 2004) connecting two environments, the plant roots and the surrounding soil (Jansa et al. 2013). The mycorrhizal hyphae extending into the soil are exposed to a great number of diverse biotic interactions (Jansa and Gryndler 2010). However, the relationship between soil fauna diversity and mycelium has been poorly studied. It is well known that the hyphae attract diverse soil mesofauna composed by a wide range of highly abundant life-forms, accounting for about $85 \%$ of the microarthropods in forest soils (Hope 2003). The mesofauna includes mites and collembolans among others, having important roles in the decomposition of organic matter, carrying out the initial fragmentation and comminution of litter (Swift et al. 1979; Petersen and Luxton 1982; Seastedt 1984; Orgiazzi et al. 2016; Frouz 2018) and transforming ingested plant debris into humus-rich fecal pellets that improve soil structure (Cassagne et al. 2003; Maaß et al. 2015).

Interactions between ectomycorrhizal mycelium and soil mesofauna are far more complex than that of consumer-resource interaction, being evidently mutualistic (Hernández-Santiago et al. 2020). These interactions can be seen during all mycorrhizal fungal life-cycle, from spore dispersal dynamics to direct stimulus to fungal growth by grazing mycelium (Fitter and Garbaye 1994; Crowther et al. 2011); fungivory is widespread among soil invertebrates (Ruess and Lussenhop 2005; Bokhorst and Wardle 2014). However, fungivores show feeding preferences between different groups of fungi (Visser and Whittaker 1977; Hiol et al. 1994; Schneider et al. 2005; Hernández-Santiago et al. 2020) and can be highly selective when foraging on soil fungi (Jørgensen et al. 2003; Jørgensen et al. 2005; Bluhm et al. 2019). The mesofauna also feed on sporomes, having a direct effect on spore dispersal (Behan and Hill 1978; Lilleskov and Bruns 2005; Hernández-Santiago et al. 2020); a very efficient spreading mechanism for taking advantage of the searching behavior of microarthropods to reach new sites (Deacon 2006).

The interactions between ectomycorrhizal mycelium and mesofauna have been mainly studied under con- trolled laboratory conditions. Under this approach, the studies of Hiol et al. (1994), who examined in vitro culture, the feeding preferences of Proisotoma minuta on ectomycorrhizal fungi, demonstrated that these varied among ectomycorrhizal species. On the other hand, Schneider et al. (2005) showed that feeding preferences significantly differed between oribatid mite species and that they preferentially selected dark-pigmented fungi (Mitchell and Parkinson 1976; Maraun et al. 1998; Schneider and Maraun 2005) over hyaline fungi when both types were offered as food items (Mitchell and Parkinson 1976). According to Fogel (1988), much of the research about soil biota-fungi interactions has focused on host-pathogen interactions rather than on their role in ecosystem processes.

Ectomycorrhizal inoculation is a simple and reliable technology used in Mexico during the last two decades, using ground pilei of edible ectomycorrhizal mushrooms to inoculate forest tree species (Pérez-Moreno et al. 2019, 2020). Inoculation with a specific ectomycorrhizal fungus, such as those of the genus Hebeloma and Laccaria (Carrasco-Hernández et al. 2011, 2015; Martínez-Reyes et al. 2012) on pine roots, could be a reliable way to study if the ERM of a single ectomycorrhizal fungal species may influence mesofauna assemblages; this can be achieved by analyzing the ectomycorrhizal roots. In general, the relationship between ERM and mesofauna has received little attention, despite its paramount importance for ecological functions in forests ecosystems. The aim of this study was to evaluate the abundance and community composition of the mesofauna inhabiting the ERM associated to Pinus greggii ectomycorrhizal roots inoculated with three different ectomycorrhizal fungi. We raise the hypothesis that there is an effect of the type of ectomycorrhizal mycelium on the soil mesofauna assemblages. Additionally, we evaluated the feeding preferences of collembolans and mites among the ectomycorrhizal species and their trophic niches in relation with their life forms according to Potapov et al. (2016).

\section{MATERIALS AND METHODS}

\section{Plant material and inoculum}

This study was conducted under greenhouse conditions in the nursery facilities at the Colegio de Postgraduados in Montecillo, State of Mexico, Mexico. We 
used trees from an ectomycorrhizal inoculation experiment established by Martínez-Reyes et al. 2010. The Pinus greggii Engelm. ex Parl. was selected because it is an endemic Mexican pine that grows in the Sierra Madre Oriental, being abundantly used in Mexico's reforestation programs (Ramírez-Herrera et al. 2005). The P. greggii seeds, used for sowing, were collected from native forests located in the Nevado de Toluca National Park, in the State of Mexico. Laccaria laccata s.l. (Scop.) Cooke and Hebeloma mesophaeum s.I. (Pers.) Quél. were the two edible ectomycorrhizal fungi used to inoculate P. greggii; these species are early colonizers (Nara et al. 2003; Obase et al. 2007) and grow in low fertility conditions (Trocha et al. 2007).

The accurate description of the morphology of the morphotypes of the studied species has already been published by Carrasco-Hernández et al. (2011, 2015) and Martínez-Reyes et al. (2012) as well as their molecular characterization; GenBank accession numbers KY969630 and MF034059 for L. laccata and H. mesophaeum, respectively. The sporomes used as source of inoculum were purchased in the local market of Ozumba, in the State of Mexico; the wild mushrooms were collected from San Pedro Nexapa forests, State of Mexico. The spore inoculum was obtained from the pilea of sporomes, being cut from the stipe, and dehydrated at $35{ }^{\circ} \mathrm{C}$ for 48 hours; finally, grinded and sieved to homogenize the inoculum particle size (see Carrasco-Hernández et al. 2011; Martínez-Reyes et al. 2012 for the full inoculation method). Wilcoxina sp. is an abundant ectomycorrhizal fungus with dark brown mycelium that does not produce fruiting bodies and commonly colonizes pine roots in native forest of Central Mexico.

In this study, it was included a dark brown ectomycorrhizae due to the fact that collembolans and oribatid mites preferentially feed on dark pigmented fungi (Mitchell and Parkinson 1976), such as those of the Dematiaceae family (Maraun et al. 1998; Schneider and Maraun 2005). However, it has not yet been reported whether dark-brown ectomycorrhizal mycelium might be a food resource to mesofauna.

\section{Setting up of the experiment and experimental design}

The experiment was set up using tree pots of $5.5 \mathrm{x}$ $18 \mathrm{~cm}$ (diameter $x$ height) and $320.7 \mathrm{~cm}^{3}$ of capacity. A mixture of sand, bark and forest soil in a 2:2:1 ratio was used as substrate, which was sterilized with steam for three hours, then after 24 hours the process was repeated (Martínez-Reyes et al. 2012), prior to fill the tree pots. Seeds were sterilized with $30 \% \mathrm{H}_{2} \mathrm{O}_{2}$ for 20 minutes and rinsed four times with sterile distilled water, before being directly planted in the containers with the substrate described above. Once the P. greggii seeds germinated and produced their first true leaves, 36 days after sowing, they were inoculated. A second inoculation dose was applied 90 days later (for details, see Carrasco-Hernández et al. 2011; Martínez-Reyes et al. 2012). In total each plant received $10^{7}$ to $10^{8}$ spores of $\mathrm{H}$. mesophaeum or L. laccata, contained in $3 \mathrm{~g}$ of dry inoculum. Spore inoculum concentration counting was carried out by using a Neubauer chamber (Marienfeld, Lauda-Königshofen, Germany) following Rentería-Chávez et al. (2017).

The inoculation method used for Wilcoxina sp. was different compared to that used for the other two ectomycorrhizal fungi. This was based on the fact that Wilcoxina sp. abundantly colonizes the roots of Pinus ayacahuite and the sampling of ectomycorrhizas of this fungus is quite easy due to its characteristic morphoanatomical features, including their characteristic dark-brown mycelium with a high mycelial density which form mycelial patches and their simple straight morphotypes (Figure 1) (DEEMY 2018); in contrast, this fungus does not produce visible ascomata.

Thus, the inoculum source for Wilcoxina sp. consisted in $10 \mathrm{~g}$ of ectomycorrhizal root tips collected in a Pinus ayacahuite stand located in the Monte Tlaloc, San Pablo Ixayoc, Texcoco, State of Mexico. Previously, it was carried out morphological and molecular identification of Wilcoxina sp. in this forest stands (Carrera-Martínez 2017). As the final goal was to produce heavily colonized mycorrhizal plants, the different inoculation techniques used to produce them, did not affect the study rationale.

The treatments consisted in inoculating Pinus greggii with the ectomycorrhizal fungi: i) Hebeloma mesophaeum; ii) Laccaria laccata and iii) Wilcoxina sp. were kept in different growing support trays, in order to avoid cross-contamination. After six months of colonization, the seedlings were arranged in a completely randomized experimental design with 3 treatments and 7 replicates per treatment, having a total of 21 experimental units, each one consisting in an inoculated tree. The twenty-one seedlings were maintained for 7 years, all of them survived. 

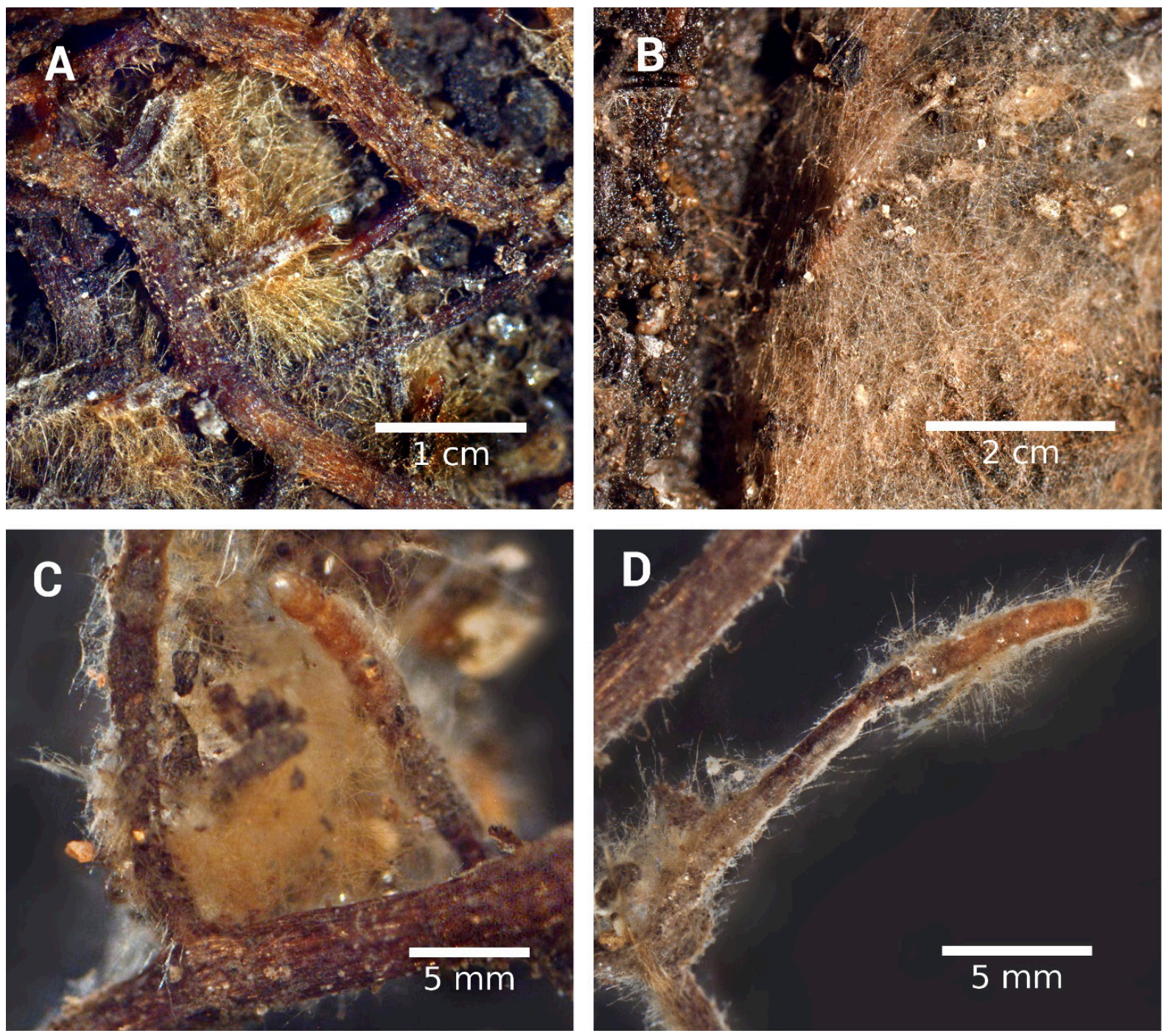

Figure 1. Morphological characterization of Wilcoxina sp. A: Mycelial patch. B: A close up of dark-brown external mycelium. C and D: Simple straight morphotypes.

The maintenance of this period of time is related with the fact that Wilcoxina sp. external mycelium is known to grow very slowly. After this time, a meticulous analysis was conducted in order to determine the colonization percentage of ectomycorrhiza and the external mycelium development in all plants. This analysis showed that ectomycorrhizal colonization and external mycelium development was quite variable among experimental units. Thus, in order to made valid comparisons among treatments, only those plants having at least $80 \%$ of ECM colonization and the external surface of the root balls completely covered with external mycelium of the inoculated fungi were selected; morphotyping was carried out following DEEMY (2018). Only 3 replicates per treatment filled the two requested criteria mentioned above.

\section{Mesofauna extraction and identification}

Mesofauna was collected from the root balls of three replicates per treatment selected as mentioned above, using a modification of the washing method of Karasawa and Hijii (2005). The root ball was cut into 4 pieces and each piece was immersed in a plastic container with tap water (ca. 1L). Roots with mycelium were washed to remove the soil and the soil solution was stirred several times for 2 hours and then filtered using stainless steel meshes; collembolans and mites were trapped by the $0.15 \mathrm{~mm}$-mesh sieve and stored in vials containing $70 \%$ ethanol. Mesofauna were separated and sorted under a Zeiss Stemi DV4 stereo microscope. For species identification, morphotypes were previously cleared with $85 \%$ lactic acid or lactophenol solution before mounting in Hoyer's 
medium and slices were dried at $45{ }^{\circ} \mathrm{C}$ for $4-5$ days, using a drying oven; mounted specimens were identified to genus or species level under a phase contrast microscope (Zeiss Axiostar Plus). Collembolans were identified using the keys of Christiansen and Bellinger (1998) and Bellinger et al. (1996-2018) and mites according to a manual of acarology (Krantz and Walter 2009).

\section{Statistical analysis}

Abundances of mesofauna expressed as the total number of individuals per tree pot $\left(320.7 \mathrm{~cm}^{3}\right)$ were used to estimate the total abundance of mites and collembolans that inhabited on the ERM of $P$. greggii ectomycorrhizal roots inoculated with the three fungal species described above. Abundances were analyzed with a completely randomized design with 3 treatments and 3 replicates per treatment with perANOVA (permutational analysis of variance) and a level of significance of $\alpha=0.05$; Monte Carlo $p$-values (pmc). This is an approach to avoid problems with non-normal data and unequal variances and to use with one variable response (Anderson 2005). PerANOVA was based on Euclidian distance and ectomycorrhizal species as fixed factor, and was carried out in PERMANOVA software version 1.6; which is a FORTRAN computer program for testing ANOVA experimental designs on the basis of distance measurements using permutation methods (Anderson 2001, 2005). Before statistical analysis, data were $\log$-transformed $\left(x^{\prime}=\log (x)\right)$.

Individual-based rarefaction curves were used to compare species richness among the mesofauna inhabiting the ERM of the three ectomycorrhizal species. Because richness increases with sample size, rarefaction computes comparable species richness adjusted for the same number of individuals collected, which will be the total abundance for the smallest of the assemblages (Colwell et al. 2012); this is also referred to as sampling effort standardized for comparable levels of abundance (Buddle et al. 2005). The pooled abundance data, based on all the species found, in each ectomycorrhizal fungi was used to compute the rarefaction estimates using the 'vegan' package in R statistical software version 3.2.5 (R Development Core Team 2016).

Permutational Multivariate Analysis of Variance (PERMANOVA Anderson 2001) was used to test the null hypothesis of no difference in the soil mesofauna communities due to the effect of ectomycorrhizal fungus.
This analysis was performed in PERMANOVA v.1.6 (Anderson 2005) based on one-way design and using Bray-Curtis dissimilarity distance measure and the test of significance ( $\alpha=0.05$ ) estimated after 9999 unrestricted permutations. Hellinger-transformed species data was used because it allows comparisons among samples with varying sampling effort and also reduces the effect of several very abundant species keeping the variations in relative species composition per sample (Borcard et al. 2011).

Species-dominance metric as defined by Pinzón and Spence (2010) was computed to show the degree of dominance or commonness of the total number of species found in the mycelium of the three ectomycorrhizal species. The dominance value (DV) was calculated for each species as a product of the relative proportional abundance $(w)$ and proportional presence (AP) and then being relativized each of the obtained values with respect to the total sum of all DV values, resulting in a relative dominance value (DV') for each species in the assemblage. Additionally, the sum of all dominance values is 1.0 (or $100 \%$ ) and therefore the more abundant and frequent the species is in relation to the other species in the assemblage, the closer its dominance value (DV') is to 1.0. According to a dominance plot, thresholds have been defined for dominant (Dom), subdominant (SubD), common (Com) and uncommon (UCom) species.

\section{RESULTS}

\section{Mesofauna abundances}

A total of 680 individual mites and collembolans, including 7 families, 12 genera and 15 species were identified in the present study (Table 1). Of these, 301 individuals of 11 species were collected from the ERM of $L$. laccata, 130 individuals of 9 species from $H$. mesophaeum, and 249 individuals of 6 species from Wilcoxina sp. (Table 1); twelve species belonging to Collembola (91.6 \%) and only three species to Acari (8.4\%). The most abundant collembolans were Mesaphorura florae (59.6\%), Hemisotoma thermophila (15\%), Proisotoma subminuta (6.5\%) and Mesaphorura yosiii (5.7 $\%)$. Only mites of the order Mesostigmata and suborder Endeostigmata were found in the mycelium of the three species of ectomycorrhizal fungi, being identified Protogamasellus mica (5\%), Alicorhagia usitata (3.1\%) and Asca garmani (0.3\%). 
Although there was no statistical difference among mesofauna abundances (pseudo- $F_{[2,6]}=0.799, p=0.5031$ ), the highest average abundance of mesofauna was found in L. laccata (100 individuals per $320.7 \mathrm{~cm}^{3}$ ), intermediate in Wilcoxina sp. and the lowest abundances in H. mesophaeum (83 and 43 individuals per 320.7 $\mathrm{cm}^{3}$, respectively). The lack of statistical significance among the different abundance values was probably due to the high dispersion of the total number of individuals captured in each root ball sampled. The largest within-root balls abundance variation was observed with Wilcoxina sp. (Figure 2), most likely as a result of the high density of hyphae that it produces (Figure 1b) and the sample size $(n=3)$.

\section{Species richness}

Species richness curves followed an curvilinear shape which was a good indication of appropriate sampling to make reliable comparisons of species richness (Buddle et al. 2005; Colwell et al. 2012) among the mesofauna that lived on the ERM on the roots of $P$. greggii inoculated with L. laccata, H. mesophaeum and Wilcoxina sp.

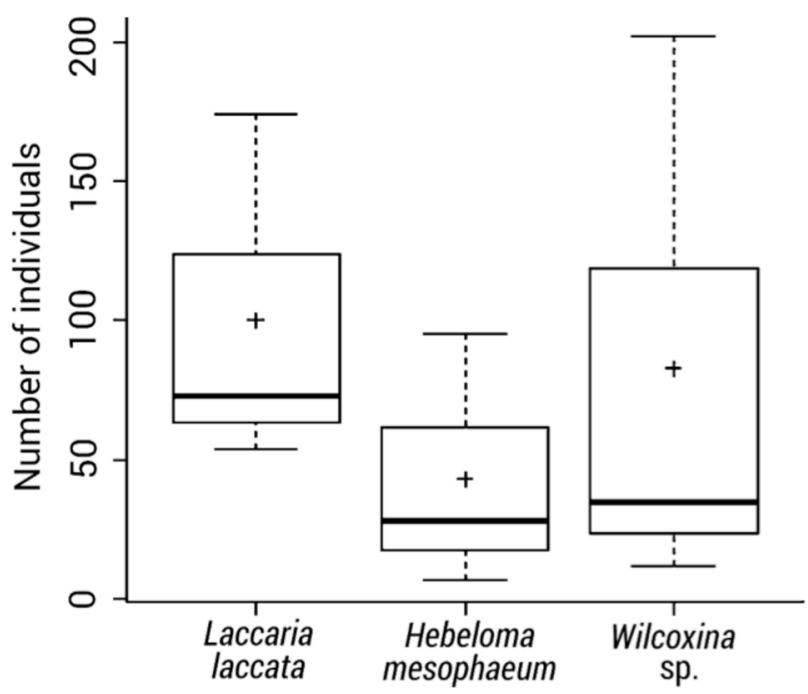

Figure 2. Abundances of Collembola and Acari found in the extraradical mycelium of Pinus greggii roots with three ectomycorrhizal fungi: Laccaria laccata, Hebeloma mesophaeum and Wilcoxina sp., expressed as number of individuals per tree pot $\left(320.7 \mathrm{~cm}^{3}\right)$. Note: The plus sign $(+)$ indicates the average abundance $(n=3)$.

Table 1. Relative abundances of mesofauna (collembolans and mites) from the extraradical mycelium of Pinus greggii of three species of ectomycorrhizal fungi: Laccaria laccata, Hebeloma mesophaeum and Wilcoxina sp., under greenhouse conditions

\begin{tabular}{|c|c|c|c|c|c|}
\hline High taxonomic rank & Family & Species name & $\begin{array}{l}\text { Laccaria } \\
\text { laccata }\end{array}$ & $\begin{array}{l}\text { Hebeloma } \\
\text { mesophaeum }\end{array}$ & Wilcoxina sp. \\
\hline \multicolumn{6}{|l|}{ Class Collembolla } \\
\hline \multirow[t]{8}{*}{ Order Poduromorpha } & Tullbergiidae & Mesaphorura florae & $36.8(16.5)$ & $71.6(4.2)$ & $65.5(11.9)$ \\
\hline & & (Simon, Ruiz, Martin \& Luciañez, 1994) & & & \\
\hline & & Mesaphorura yosiii (Rusek, 1967) & $0.0(0.0)$ & $0.0(0.0)$ & $6.4(6.4)$ \\
\hline & & Mesaphorura iowensis (Mills, 1932) & $0.6(0.6)$ & $0.0(0.0)$ & $0.0(0.0)$ \\
\hline & Hypogastru- & Mitchellania ca. vulgaris & $0.2(0.2)$ & $2.8(2.8)$ & $0.0(0.0)$ \\
\hline & ridae & Ceratophysella ca. gibbosa & $0.0(0.0)$ & $0.4(0.4)$ & $0.0(0.0)$ \\
\hline & & Hypogastrura ca. harveyi & $0.0(0.0)$ & $0.7(0.7)$ & $0.0(0.0)$ \\
\hline & & Schoettella distincta (Denis, 1931) & $0.0(0.0)$ & $0.4(0.4)$ & $0.0(0.0)$ \\
\hline \multicolumn{6}{|l|}{ Order } \\
\hline \multirow{5}{*}{ Entomobryomorpha } & & Hemisotoma thermophila (Axelson, 1900) & $20.8(14.0)$ & $2.6(1.3)$ & $1.0(1.0)$ \\
\hline & Isotomidae & Proisotoma subminuta (Denis, 1931) & $16.6(14.4)$ & $7.4(3.5)$ & $20.5(15.1)$ \\
\hline & & Proisotoma minima (Absolon, 1901) & $10.5(10.5)$ & $0.0(0.0)$ & $0.0(0.0)$ \\
\hline & & Lepidocyrtus sp. & $0.6(0.6)$ & $0.0(0.0)$ & $0.0(0.0)$ \\
\hline & Entomobryidae & & & & \\
\hline Order Neelipleona & Neelidae & $\begin{array}{l}\text { Megalotorax perspicillum (Schneider \& D’Haese, } \\
\text { 2013) }\end{array}$ & $0.6(0.6)$ & $0.0(0.0)$ & $0.0(0.0)$ \\
\hline \multicolumn{6}{|l|}{ Subclass Acari } \\
\hline Order Mesostigmata & & Protogamasellus mica (Athias-Henriot, 1961) & $8.6(3.5)$ & $6.0(4.3)$ & $2.9(2.9)$ \\
\hline & Ascidae & Asca garmani (Hurlbutt, 1963) & $1.1(0.6)$ & $0.0(0.0)$ & $0.0(0.0)$ \\
\hline \multicolumn{6}{|l|}{ Suborder Endeostigmata } \\
\hline & & Alicorhagia usitata (Theron, Meyer \& Ryke, 1970) & $3.5(2.0)$ & $8.3(8.3)$ & $3.8(2.4)$ \\
\hline & Alicorhagiidae & & & & \\
\hline Total* & 7 & 12 & 11 & 9 & 6 \\
\hline
\end{tabular}

*Total number of families, genera or species recorded. Note: Relative abundance values are means $(n=3)$ and standard error given in parentheses. 
Rarefied species richness was standardized by the minor number of individuals collected, which was 130 individuals, to allow meaningful comparisons of species richness and to take into account sampling effort (Buddle et al. 2005). The rarefaction curves showed that species richness was lowest in Wilcoxina sp. (5 spp.) compared to L. laccata and $H$. mesophaeum, both of which recorded the highest richness (8 spp.); thus, no differences were detected between these two ectomycorrhizal fungi (Figure 3). These estimates suggest a relationship between the species richness of mesofauna and the morphological characteristics of the mycelia of the ectomycorrhizal species where the mesofauna inhabited.

Effect of ectomycorrhizal fungi on species dominance

An initial ordination of the species data indicated no differences in species composition because there was no 2-dimensional arrangement of the points (results not shown). PERMANOVA analysis showed no effect on the community composition of the mesofauna due to influence of the ectomycorrhizal specie $\left(F_{[2,6]}=1.07\right.$, $p=0.406)$. Species dominance analysis supported PERMANOVA results indicating the presence of one highly dominant collembolan species in the root balls, Mesaphorura florae with a relative dominance value of $D^{\prime}=73.50$ (Figure 4); which may directly influence that there were no significant differences among the mesofauna communities that dwelled on the ERM of $L$. laccata, H. mesophaeum and Wilcoxina sp.; the community structure is a function of the number and relative abundances of species in a habitat (Starr et al. 2016). Furthermore, the subdominant species were Hemisotoma thermophila and Proisotoma subminuta having relative dominance values of $\left(D^{\prime}=12.34\right)$ and $\left(D V^{\prime}=6.21\right)$, respectively, as well as, Protogamasellus mica $\left(D V^{\prime}=4.11\right)$ and Alicorhagia usitata $\left(D V^{\prime}=2.12\right)$ were subdominant species belonging to Acari. Although a reduced number of species were common or uncommon, it was shown that they had a particularly preference for dwelling in a specific ectomycorrhizal mycelium. For instance, Mitchellania ca. vulgaris $\left(D^{\prime}=0.36\right)$ and Hypogastrura ca. harveyi $\left(D^{\prime} V^{\prime}=0.04\right)$ mostly inhabited in the ERM of $H$. mesophaeum and Mesaphorura yosiii $\left(\mathrm{DV}^{\prime}=0.79\right)$ dwelled in Wilcoxina sp. The predator mite Asca garmani $\left(D^{\prime} V^{\prime}=0.08\right)$ and the collembolans such as Proisotoma minima $\left(D^{\prime}{ }^{\prime}=0.34\right)$ and Mesaphorura iowensis ( $\left.\mathrm{DV}^{\prime}=0.02\right)$ were uncommon L. laccata-dwelling species. Subdominant and uncommon species may influence the results of species richness of the mesofauna that inhabited on the ERM of each ectomycorrhizal fungus.

\section{DISCUSSION}

In this paper, we attempted to define if the ectomycorrhizal mycelium may influence mesofauna assemblages because it is unknown the dynamics involved

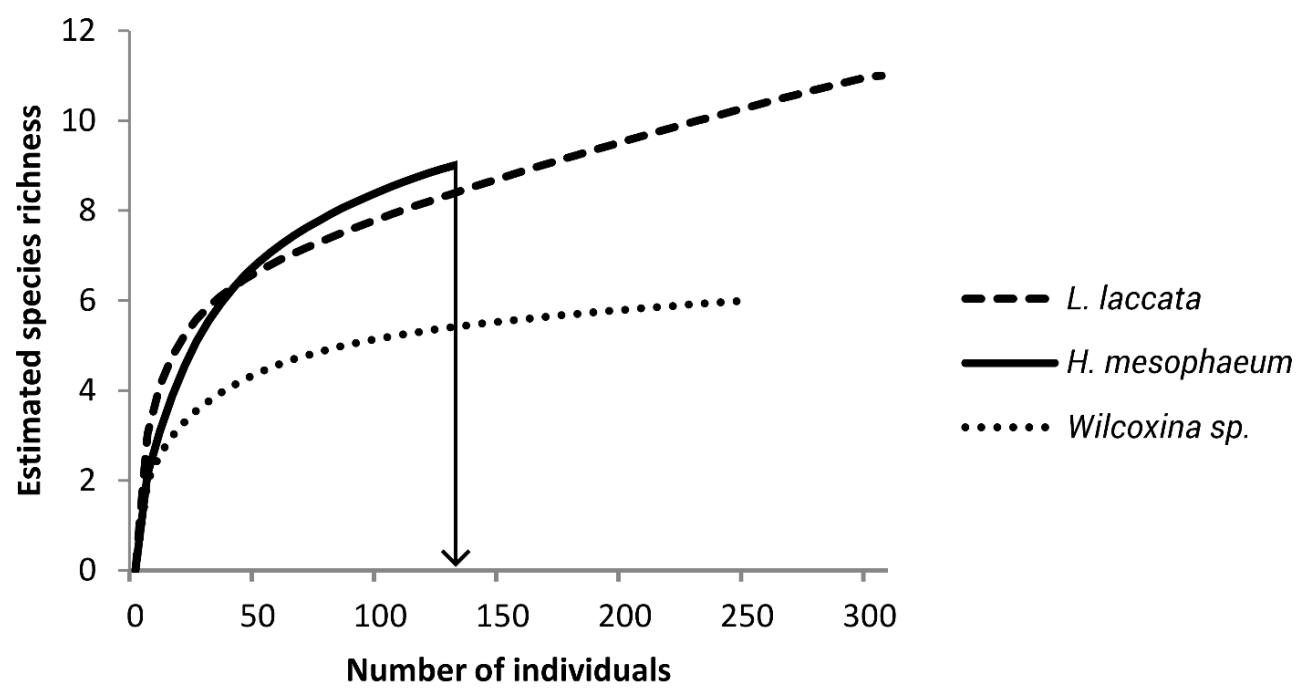

Figure 3. Individual-based rarefaction curves of estimated species richness of Collembola and Acari from the extraradical mycelium of Pinus greggii roots with three ectomycorrhizal fungi: Laccaria laccata, Hebeloma mesophaeum and Wilcoxina sp.; the estimation was standardized by minimum sample size of 130 individuals indicated by the arrow. 


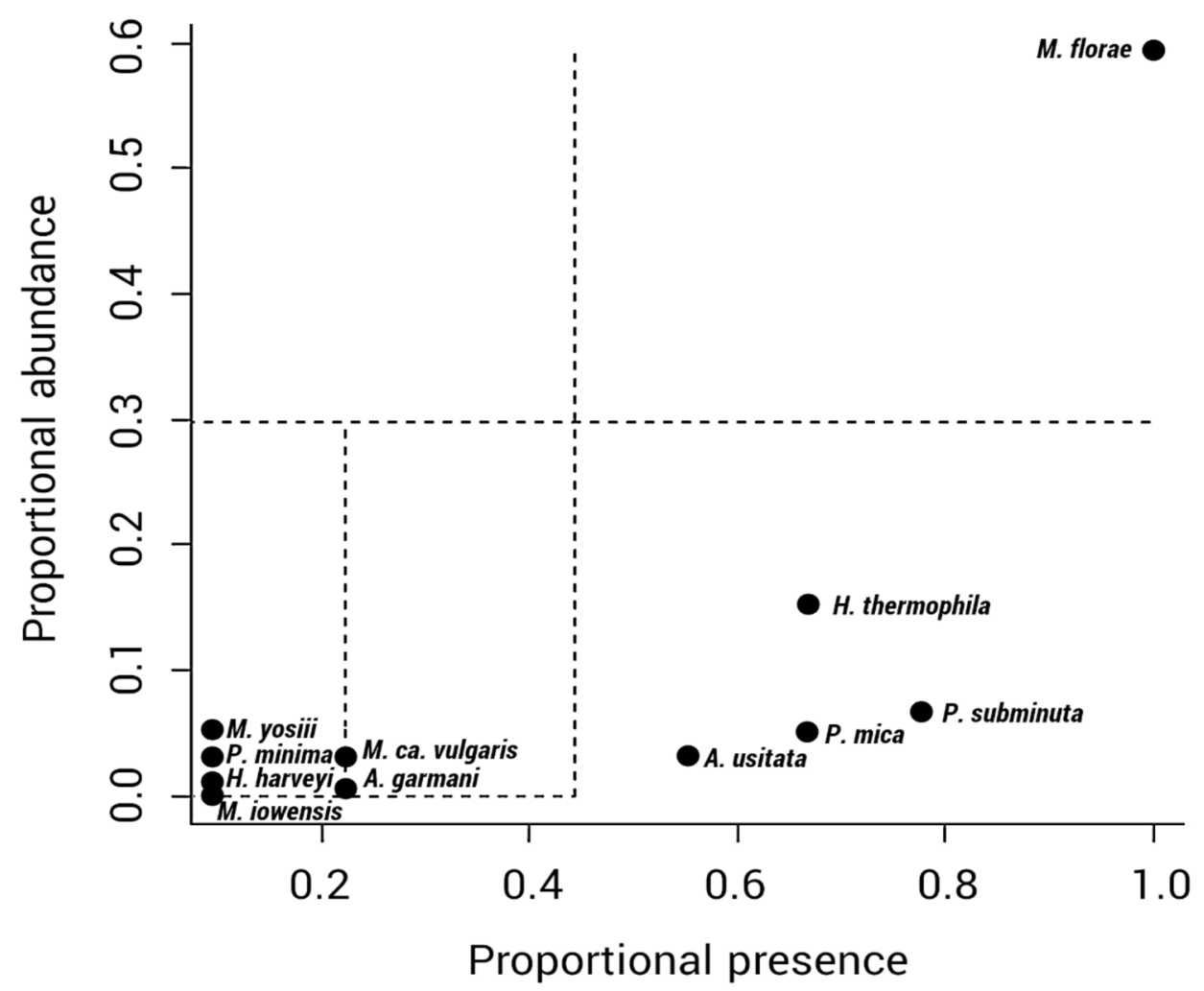

Figure 4. Dominance plot of all mesofauna (collembolans and mites) found in the extraradical mycelium of the roots of $P$. greggii with three ectomycorrhizal fungi: L. laccata, H. mesophaeum and Wilcoxina sp. Note: Dominant species in the upper right quadrant and subdominant species in the lower right quadrant. In the lower left quadrant, common species on the right and uncommon species on the left.

during the assembly processes and if ERM could provide unique biotic and abiotic characteristics to mesofauna that colonize it. In general, the results do not support our hypotheses that expected an effect on the abundance and community composition of mesofauna assemblages inhabiting on the ERM of three different ectomycorrhizal species. However, we did observe an effect on species richness and species dominance, of the total number of mesofauna species found in the three ectomycorrhizal fungi. A fully structured mesofauna assemblage naturally associated with the ERM of L. laccata, H. mesophaeum or Wilcoxina sp. was not observed because the mesofauna colonization process could be more slowly in the tree pots than in a natural environment.

On the other hand, in his microcosm experiment Setälä (1995) defaunated and reinoculated with diverse soil fauna seedlings of Pinus sylvestris infected with different ectomycorrhizal fungi, obtaining an abundant and taxonomically diverse mesofauna to evaluate the impact of soil fauna on ectomycorrhizal biomass. However, the goal of this study was to know if the co-
Ilembolans and mites could choose for themselves an ectomycorrhizal species which could provide them an adequate habitat and food resources. A surprising notable absence was that of oribatid mites, constituting one of the major litter dwelling mycophagous that feed on ectomycorrhizal and saprotrophic fungi (Schneider et al. 2005; Schneider and Maraun 2005). In this regard, Booth and Swanton (2002) mentioned that dispersal constrains determine what species arrive at a site. In this study, it was assumed that there was a continuous arrival of collembolans and mites at the tree plots; however, this was not the case for oribatid mites, considering their low dispersal ability (Lebrun and van Straalen 1995), they could not colonize the tree pots. Whereas collembolans rapidly expanded their distribution, especially for their dispersal ability and high reproduction rates.

According to Maharning et al. (2009) the two factors that influence the soil communities are the nutrient resources available and the microhabitat diversity as well as the trophic niches related to taxonomic identity and life forms (Potapov et al. 2016). Collembolans 
such as the genera Mesaphorura, being characterized as soil-dwelling (euedaphic) taxa, were the most abundant dwellers (Table 1). Stebaeva (1970) and Potapov et al. (2016) indicated that adaptations to dwelling in deeper soil layers are expressed by minute body length, lack of pigmentation, no eyes, furcula absent and short legs. The degree of occurrence was confirmed by the high abundance and presence of the Mesaphorura species in the tree pots; therefore, isotomid-tullbergid collembolans are the most closely related to inhabit the soil and mycelium. Adaptations to life on the surface of soil (epedaphic species) were evidenced for the presence of species of the Entomobryidae and Hypogastruridae families; these collembolans were of large to medium-size, with furcula, frequently pigmented and with ocelli (Potapov et al. 2016). However, they were not dwellers in Wilcoxina due to habitat restrictions such as non-formation of sporomes.

Effect of the ectomycorrhizal fungi on mesofauna species richness Assessment of the three ectomycorrhizal fungi L. laccata, H. mesophaeum and Wilcoxina sp. clearly showed that the ERM have an effect on species richness. Changes in species richness may reflect the habitat availability associated with the different mycelial morphology which is highly dependent on the intrinsic genetics of the ectomycorrhizal fungi. For example, the low species richness from the dark mycelium of Wilcoxina could be related to high density, thickness or tangled mass of hyphae that form its mycelium in comparison with less dense hyphal strands of $L$. laccata and H. mesophaeum. Previously, it has been demonstrated that the extent and structure of ERM differ among ectomycorrhizal fungal taxa, particularly in terms of emerging hyphae and rhizomorphs (Agerer 2001). From the viewpoint of mesofauna distribution in this study, it seem to be unevenly distributed among the three ectomycorrhizal mycelia and, at the same time, L. laccata and $H$. mesophaeum mycelia hosted quite different species of collembolans (Table 1). The higher species richness shared by $H$. mesophaeum and $L$. laccata highlights the importance of the low mycelial density and hyaline mycelium to support higher species richness compared to Wilcoxina treatment, which had abundant dark brown external mycelium which frequently forms mycelial patches. Our results revealed that a higher mesofauna diversity dominated on the hyaline mycelium of edible ectomycorrhizal species in comparison with that on the dark brown mycelium of ectomycorrhizal fungi.

On the other hand, H. mesophaeum showed higher abundance of epedaphic species, corresponding to upper-litter dwellers such as Lepidocyrtus sp. and species of the family Hypogastruridae (Stebaeva 1970; Potapov et al. 2016), this take place with the apparition of the sporomes. It was found that Mitchellania ca. vulgaris showed spores in their digestive tract as evidence of feeding on the sporomes produced in the tree pots (Figure 5) and of participating actively in the dissemination of spores. It may be that Wilcoxina sp. did not present a higher diversity because it does not produce epigeous fruiting bodies. Our results indicate that the taxonomical composition of the mesofauna richness may be a result in terms of nature of mycelium and of fungal production of sporomes but not in terms of the ectomycorrhizal species. These findings may be considered an unknown ecological phenomenon as no previous research has identified the role of the ERM ectomycorrhizal fungi contributing to differences in mesofauna species richness. Increasing species richness leads to an increase of diversity and ecosystem functioning. However, future research in this area is needed to have more detailed evidence about the factors that influence the formation of mesofauna community structure due to the mycelium of ectomycorrhizal species.

Dominance structure of mesofauna associated to ectomycorrhizal mycelium

Our appreciation of other roles of the ERM is hampered by a lack of understanding of mycelial systems. The mycelial network provides useful insights into the food web dynamics and life forms of mesofauna inhabiting the ERM and these can be viewed analyzing the dominance structure of mesofauna. In this study, we can assume that the degree of mesofauna aggregation in the sampled tree pots was related to the morphology of mycelium creating habitats, which allow the dwelling of species of different trophic niches. The observed presence of collembolan and mite species from the mycelium of the three ectomycorrhizal fungi within the different quadrants of the dominance plot (Figure 4) can be explained by species behavior and life forms. The number of taxa of collembolans (saprophages and mycophages) and predaceous mesostigmatic and endeostigmatic mites in general pre- 
dominated during the development of the mycelium; collembolans were by far the most numerous colonizers.

In an immigration test plots, Dunger et al. (2002) proved that Mesaphorura florae has been transported by air and that it could form stable populations after 4 months and show a noticeable proliferation, being registered as an early colonizers and as a of the dominant species in the plots. Similarly, but in this case under greenhouse conditions, it was found that $M$. florae was the dominant species (Figure 4) and it was considered as the species that first colonized the mycelium. Our findings tend towards the presumption that $M$. florae was the pioneer species with a rapid propagation and that it is able to survive in the ERM of the three ectomycorrhizal fungi. The other possible initial colonizers, Proisotoma subminuta, was also present in the three ectomycorrhizal mycelia but with a much lower abundance. The two species showed high abundance on the ERM and this was related to their life forms corresponding to the euedaphic group (Stebaeva 1970). On the contrary, $P$. minima had only preference for dwelling on the mycelium of L. laccata (Table 1). Grazers of the fungal food chain are fungus-feeding collembolans, which shape species-rich assemblages (Scheu and Setäla 2002) and they were mainly found in this study due to formation of functional groups, which implies that collembolans are grouped according to their taxonomic identity, life forms and food sources (Potapov et al. 2016). For example, the species of the genus Mesaphorura were commonly viewed consuming large quantities of detritus (Figure $6 \mathrm{a}$ and $6 \mathrm{~b}$ ) but also are fungal hyphae feeders (Ponge 2000), corresponding to euedaphic species (Potapov et al. 2016). Lepidocyrtus sp. showed mycelial hyphae of L. laccata in its digestive tract (Figure $6 c$ and $6 d$ ), despite living preferentially near the surface (epedaphic) (Stebaeva 1970; Potapov et al. 2016). The species of Hypogastruridae were the other upper-litter dwellers (epedaphic) that showed gut contents composed mainly of spores, being associated as potential spore-dispersers for dwelling on the fruit bodies of $\mathrm{H}$. mesophaeum (Figure 5).
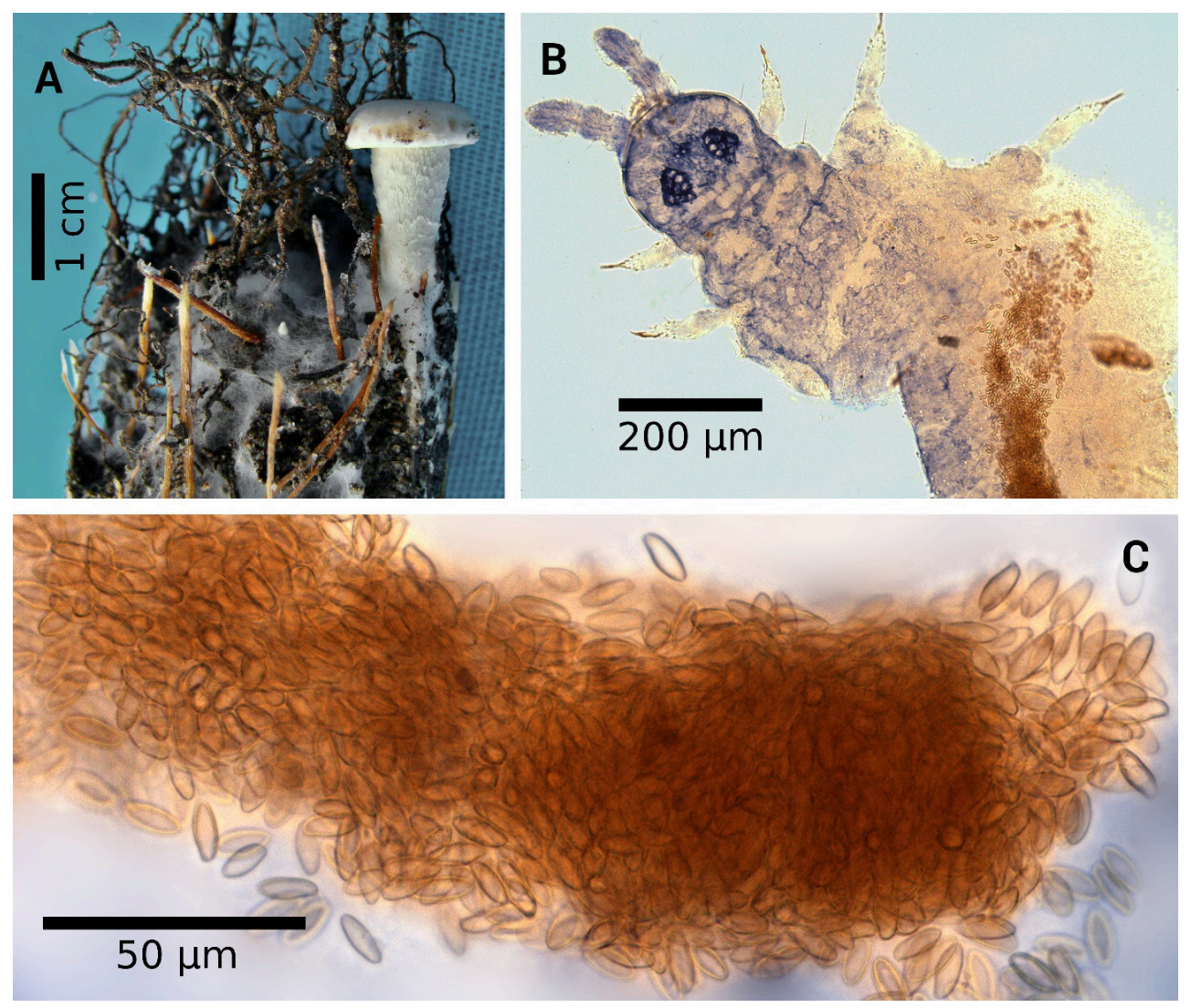

Figure 5. A: Sporome of Hebeloma mesophaeum. B: Mitchellania ca. vulgaris found dwelling on sporome of H. mesophaeum. C: Spores of H. mesophaeum in the digestive tract of $M$. ca. vulgaris. 

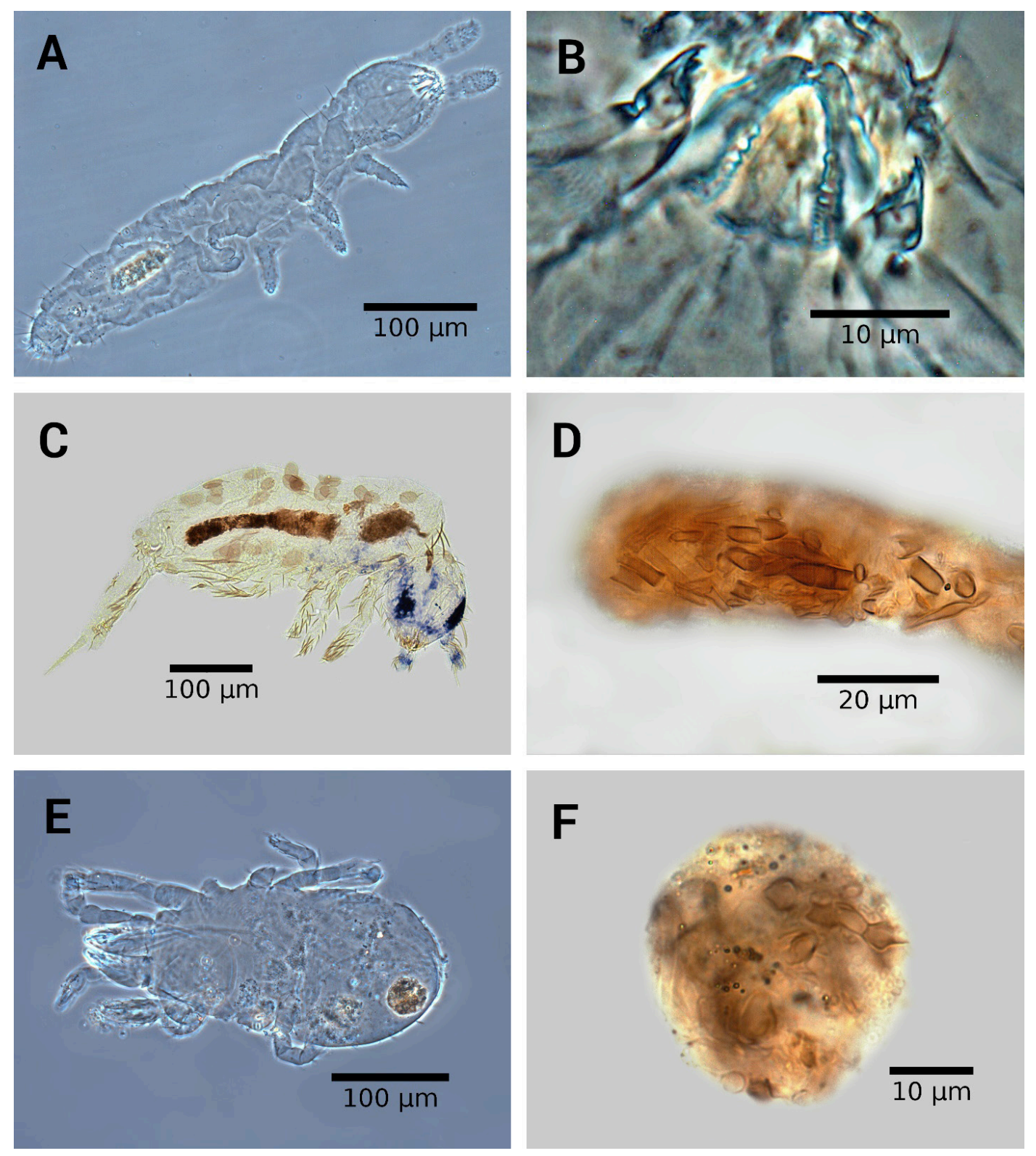

Figure 6. A: Soil and hyphae dwelling Mesaphorura florae. B: Chewing mouthparts of M. florae with very developed molar area in the jaws to triturate detritus and fungi. C: Lepidocyrtus sp. found dwelling on Laccaria laccata. D: Hyphae of L. laccata in the digestive tract of Lepidocyrtus sp. E: Alicorhagia usitata found dwelling on Wilcoxina sp. F: Hyphae of Wilcoxina sp. in the gut content of A. usitata.

In relation to the species of Acari, it was found that Alicorhagia usitata feeds on the hyphae of Wilcoxina sp. (Figure 6e and 6f). Walter et al. (1988) mentioned that Endeostigmata are important nematophages and that the species of Alicorhagiidae are best considered omnivores; when nematodes are not available, the adults feed on fungi. Contrary to what was reported by Schneider and Maraun (2005), a feeding preference for dark pigmented mycelium was not observed because we did not find evidences in the gut contents of the other species (excepting some indi- viduals of Mesaphorura) that inhabited the mycelium of Wilcoxina sp. Finally, Walter et al. (1988) showed that Protogamasellus mica and mites of the genus Asca presented high rates of feeding preference for nematode and collembolans preys. The presence of $P$. mica in the mycelium of the three ectomycorrhizal fungi indicate its ecological role as population regulators of the collembolan populations on the ERM, which places predatory mites in a high trophic-level in the food web of the ERM of the ectomycorrhizal fungi. 


\section{CONCLUSIONS}

The study of interactions between the mycelium of ectomycorrhizal fungi and soil mesofauna is important not only to understand the ERM functions, but also to have a broader insight of the nature of the relationships that drive and regulate ecosystem processes. Collembolans and mites dwelling the mycelium of ectomycorrhizal fungi are poorly known. We found that there was not difference in the abundance and community structure but there was an effect on species richness and species dominance of total number of mesofauna that was recorded. The dominance structure analysis helped to explain the interaction of the mesofauna with the ERM associated to Pinus greggii roots inoculated with ectomycorrhizal fungi. It was observed a food web in terms of functional groups that share the mycelial habitat being indicated for the feeding and habitat preferences of collembolans and mites, as a result of their life forms. Otherwise, mycelium is composed of a filamentous network of hyphae which might conforms diverse habitats for mesofauna depending of the filament elasticity, hyphae filament diameter, branching and network density as well as fruiting body formation. Wilcoxina sp. presents a high network density and branching that showed few soil mesofauna taxonomic groups dwelling the mycelium, expressed as a low species richness, compared to the less network density of the mycelium of $L$. laccata and $H$. mesophaeum. Properties of the mycelium result in the formation of trophic niches in relation to life forms of mesofauna shaping the food web on the ERM among the different ectomycorrhizal fungi studied and, therefore the mycelium might be an evolutionary force in structuring species composition, diversity, and stability of mesofauna communities.

\section{ACKNOWLEDGEMENTS}

The authors gratefully acknowledge financial support for this research of the project CONACyT 246674 "Biotecnologías de los hongos comestibles ectomicorrízicos y su impacto en la mitigación del cambio climático y desarrolllo forestal". JPM acknowledges CONACyT 2018-000007-402 01EXTV and COMECyT for the financial support to carry out an international sabbatical stay in the Kunming Institute of Botany, 403 Chinese Academy of Sciences in Kunming, China. Special thanks to Drs. José G. Palacios-Vargas, Roy Norton, Samuel Bolton, Wayne Knee and Vladimír Papáč as well as MSc. Jesús I. Cruz-Leal for providing taxonomic advice, species identification and taxonomic corroboration.

\section{REFERENCES}

Agerer R. 2001. Exploration types of ectomycorrhizae. Mycorrhiza 11, 107-114. https://doi-org/10.1007/s005720100108

Anderson MJ. 2001. A new method for non-parametric multivariate analysis of variance. Austral Ecology 26, 32-46. https://doi.org/1 0.1111/j.1442-9993.2001.01070.pp.x

Anderson MJ. 2005. PERMANOVA: a FORTRAN computer program for permutational multivariate analysis of variance. University of Auckland, Auckland.

Behan MV, Hill SB. 1978. Feeding habits and spore dispersal of Oribatid mites in the North American Arctic. Revue d'Ecologie et de Biologie du Sol 15, 497-516.

Bellinger PF, Christiansen KA, Janssens F. 1996-2018. Checklist of the Collembola of the World. http://www.collembola.org. (Consulted June to October, 2018).

Bluhm SL, Potapov AM, Shrubovych J, Ammerschubert S, Polle A, Scheu S. 2019. Protura are unique: first evidence of specialized feeding on ectomycorrhizal fungi in soil invertebrates. BMC Ecology 19, 10. https://doi.org/10.1186/s12898-019-0227-y

Borcard D, Gillet F, Legendre P. 2011. Numerical Ecology with R. Use R! Series. Springer Science, New York.

Buddle CM, Beguin J, Bolduc E, Mercado A, Sackett TE, Duncan-Selby R, Varady-Szabo H, Zeran RM. 2005. The importance and use of taxon sampling curves for comparative biodiversity research with forest arthropod assemblages. The Canadian Entomologist 13, 120-127. https://doi.org/10.4039/n04-040

Bokhorst S, Wardle DA. 2014. Snow fungi as a food source for micro-arthropods. European Journal of Soil Biology 60, 77-80. https://doi.org/10.1016/j.ejsobi.2013.11.006

Booth BD, Swanton CJ. 2002. Assembly theory applied to weed communities. Weed Science 50, 2-13.

Carrasco-Hernández V, Pérez-Moreno J, Espinosa-Hernández V, Almaraz-Suárez JJ, Quintero-Lizaola R, Torres-Aquino M. 2011. Contenido de nutrientes e inoculación con hongos ectomicorrízicos comestibles en dos pinos neotropicales. Revista Chilena de Historia Natural 84, 83-96. http://doi.org/10.4067/S0716078X2011000100006

Carrasco-Hernández V, Pérez-Moreno J, Quintero-Lizaola R, Espinosa-Solares T, Lorenzana-Fernández A, Espinosa-Hernández V. 2015. Edible species of the fungal genus Hebeloma and two neotropical pines. Pakistan Journal of Botany 47, 319-326.

Carrera-Martínez A. 2017. Morphological, anatomic and molecular identification of ectomycorrhizal fungi associated to Pinus ayacahuite Ehrenberg. (In Spanish). BSc thesis Instituto Tecnológico del Valle de Oaxaca, Oaxaca.

Cassagne N, Gers C, Gauquelin T. 2003. Relationships between Collembola, soil chemistry and humus types in forest stands (France). Biology and Fertility of Soils 37, 355-361. http://doi. org/10.1007/s00374-003-0610-9

Christiansen KA, Bellinger PF. 1998. The Collembola of North America North of the Rio Grande. A Taxonomic Analysis. 2nd Edition. Grinnell College, Grinnell.

Colwell RK, Chao A, Gotelli NJ, Lin S-Y, Mao CX, Chazdon RL, Longino JT. 2012. Models and estimators linking individual-based and sample-based rarefaction, extrapolation and comparison 
of assemblages. Journal of Plant Ecology 5, 3-21. https://doi. org/10.1093/jpe/rtr044

Crowther TW, Boddy L, Jones TH. 2011. Species-specific effects of soil fauna on fungal foraging and decomposition. Oecologia 167, 535-545. https://doi.org/10.1007/s00442-011-2005-1

Deacon JW. 2006. Fungal spores, spore dormancy, and spore dispersal. Fungal Biology. 4th Edition. Blackwell Publishing, Malden.

DEEMY. 2018. An information system for characterization and determination of ectomycorrhizae. Universität München, Munich.

Dunger W, Schulz HJ, Zimdars B. 2002. Colonization behaviour of Collembola under different conditions of dispersal. Pedobiologia 46, 316-327. https://doi.org/10.1078/0031-4056-00139

Fitter AH, Garbaye J. 1994. Interactions between mycorrhizal fungi and other soil organisms. Plant and Soil 159, 123-132.

Fogel R. 1988. Interactions among soil biota in coniferous ecosystems. Agriculture Ecosystems and Environment 24, 69-85. https://doi.org/10.1016/0167-8809(88)90057-6

Frouz J. 2018. Effects of soil macro- and mesofauna on litter decomposition and soil organic matter stabilization. Geoderma 332, 161-172. https://doi.org/10.1016/j.geoderma.2017.08.039

Hernández-Santiago F, Díaz-Aguilar I, Pérez-Moreno J, Tovar-Salinas JL. 2020. Interactions between soil mesofauna and edible ectomycorrhizal mushrooms. In: Pérez-Moreno J, Guerin-Laguette A, Flores-Arzú R, Yu F-Q (eds.) Mushrooms, humans and nature in a changing world. Perspectives from ecological, agricultural and social sciences. Springer, Cham. 367-405.

Hiol FH, Dixon RK, Curl EA. 1994. The feeding preference of mycophagous Collembola varies with the ectomycorrhizal symbiont. Mycorrhiza 5, 99-103. https://doi.org/ 10.1007/BF00202340

Hope GD. 2003. Of mites and men--and springtails: a study of soil microarthropods in the Sicamous Creek alternative silvicultural systems project. B.C. Ministry of Forests, Kamloops Forest Region, British Columbia.

Jansa J, Bukovská P, Gryndler M. 2013. Mycorrhizal hyphae as ecological niche for highly specialized hypersymbionts - or just soil free-riders? Frontiers in Plant Science 4, 1-8. https://doi. org/10.3389/fpls.2013.00134

Jansa J, Gryndler M. 2010. Biotic environment of the arbuscular mycorrhizal fungi in soil. In: Koltai H, Kapulnik Y. (eds.) Arbuscular mycorrhizas: Physiology and function. Springer, Dordrecht. 209236.

Jørgensen HB, Elmholt S, Petersen H. 2003. Collembolan dietary specialisation on soil grown fungi. Biology and Fertility of Soils 39, 9-15. https://doi.org/ 10.1007/s00374-003-0674-6

Jørgensen HB, Johansson T, Canbäck B, Hedlund K, Tunlid A. 2005. Selective foraging of fungi by collembolans in soil. Biology Letters 1, 243-246. https://doi.org/10.1098/rsbl.2004.0286

Karasawa S, Hijii N. 2005. Efficiency of sampling oribatid mites (Acari: Oribatida) from the canopies of broad-leaved trees in Japan: a comparison between the washing and direct methods. Journal of the Acarological Society of Japan 14, 19-24. https://doi. org/10.2300/acari.14.19

Krantz GW, Walter DE. 2009. A Manual of acarology. 3rd Edition. Texas Tech University Press, Lubbock.
Leake J, Johnson D, Donnelly D, Muckle G, Boddy L, Read D. 2004. Networks of power and influence: the role of mycorrhizal mycelium in controlling plant communities and agroecosystem functioning. Canadian Journal of Botany 82, 1016-1045. https:// doi.org/ 10.1139/b04-060

Lebrun P, van Straalen NM. 1995. Oribatid mites: prospects for their use in ecotoxicology. Experimental and Applied Acarology 19, 361-379. https://doi.org/10.1007\%2FBF00145154

Lilleskov EA, Bruns TD. 2005. Spore dispersal of a resupinante ectomycorrhizal fungus, Tomentella sublilacina, via soil food webs. Mycologia 97, 762-769. https://doi.org/10.1080/15572536.200 $\underline{6.11832767}$

López-Gutiérrez A, Pérez-Moreno J, Hernández-Santiago F, Uscanga-Mortera E, García-Esteva A, Cetina-Alcalá VM, Cardoso-Villanueva MR, Xoconostle-Cázares B. 2018. Nutrient mobilization, growth and field survival of Pinus pringlei inoculated with three ectomycorrhizal mushrooms. Botanical Sciences 96, 286-304. https://doi.org/10.17129/botsci.1239

Maaß S, Caruso T, Rillig MC. 2015. Functional role of microarthropods in soil aggregation. Pedobiologia 58, 59-63. https://doi. org/10.1016/j.pedobi.2015.03.001

Maharning AR, Mills AAS, Adl SM. 2009. Soil community changes during secondary succession to naturalized grasslands. Applied Soil Ecology 41, 137-147. https://doi.org/10.1016/j. apsoil.2008.11.003

Maraun M, Miggie S, Schaefer M, Scheu S. 1998. Selection of microfungal food by six oribatid mite species (Oribtida, Acari) from two different beech forests. Pedobiologia 42, 232-240.

Martínez-Reyes M. 2010. Mycorrhization, growth and nutritional content of Pinus greggii and P. montezumae inoculated with three edible fungi. (In Spanish). PhD thesis, Postgrado en Edafología, Colegio de Postgraduados, Montecillo, Texcoco, Estado de México, México.

Martínez-Reyes M, Pérez-Moreno J, Villarreal-Ruiz L, Ferrera-Cerrato R, Xoconostle-Cázares B, Vargas-Hernández JJ, Honrubia-García M. 2012. Growth and nutrient contents of Pinus greggii Engelm. inoculated with the edible ectomycorrhizal mushroom Hebeloma mesophaeum (Pers.) Quél. Revista Chapingo Serie Ciencias Forestales y del Ambiente 18, 183-192. https://doi.org/10.5154/r. rchscfa. 2010.11.112

Mitchell MJ, Parkinson D. 1976. Fungal feeding of oribatid mites (Acari: Cryptostigmata) in an aspen woodland soil. Ecology 57, 302-312. https://doi.org/10.2307/1934818

Nara K, Nakaya H, Wu B, Zhou Z, Hogetsu T. 2003. Underground primary succession of ectomycorrhizal fungi in a volcanic desert on Mount Fuji. New Phytologist 159, 743-756. https://doi.org/10.1046/j.1469-8137.2003.00844.x

Obase K, Tamai Y, Yajima T, Miyamoto T. 2007. Mycorrhizal associations in woody plant species at the Mt. Usu volcano, Japan. Mycorrhiza 17, 209-215. https://doi.org/10.1007/s00572-006-0097-y

Orgiazzi A, Bardgett RD, Barrios E, Behan-Pelletier V, Briones MJI... et al. 2016. Global Soil Biodiversity Atlas. European Commission, Publications Office of the European Union, Luxembourg.

Pérez-Moreno J, Lorenzana-Fernández A, Medel-Ortiz R, Ferrera-Cerrato R, Mata-Montes de Oca G. 2019. Los hongos 
ectomicorrízicos de México: una perspectiva global. In: Álvarez-Sánchez FJ, Rodríguez-Guzmán P, Alarcón A. (eds.) Biodiversidad de microorganismos en México. Importancia, aplicación y conservación. Prensas de Ciencias, UNAM, Ciudad de México. 102-126.

Pérez-Moreno J, Martínez-Reyes M, Hernández-Santiago F, Ortiz-López I. 2020. Climate change, biotechnology, and Mexican Neotropical edible ectomycorrhizal mushrooms. In: Pérez-Moreno J, Guerin-Laguette A, Flores Arzú R, Yu FO (eds.) Mushrooms, humans and nature in a changing world. perspectives from ecological, agricultural and social sciences. Springer, Cham. 61-99.

Petersen H, Luxton M. 1982. A comparative analysis of soil fauna populations and their role in decomposition processes. Oikos 39, 288-388. https://doi.org/10.2307/3544689

Pinzón J, Spence JR. 2010. Bark-dwelling spider assemblages (Araneae) in the boreal forest: dominance, diversity, composition and life-histories. Journal Insect Conservation 14, 439-458. https:// doi.org/10.1007/s10841-010-9273-7

Ponge JF. 2000. Vertical distribution of Collembola (Hexapoda) and their food resources in organic horizons of beech forests. Biology and Fertility of Soils 32, 508-522. https://doi.org/10.1007/ s003740000285

Potapov AA, Semenina EE, Korotkevich AY, Kuznetsova NA, Tiunov AV. 2016. Connecting taxonomy and ecology: Trophic niches of collembolans as related to taxonomic identity and life forms. Soil Biology and Biochemistry 101, 20-31. https://doi.org/10.1016/j. soilbio.2016.07.002

R Development Core Team. 2016. R: A language and environment for statistical computing. R Foundation for Statistical Computing, Vienna.

Ramírez-Herrera C, Vargas-Hernández JJ, López-Upton J. 2005. Distribución y conservación de las poblaciones naturales de Pinus greggii. Acta Botanica Mexicana 72, 1-16.

Rentería-Chávez MC, Pérez-Moreno J, Cetina-Alcalá VM, Ferrera-Cerrato R, Xoconostle-Cázares B. 2017. Transferencia de nutrientes y crecimiento de Pinus greggii Engelm. inoculado con hongos comestibles ectomicorrícicos en dos sustratos. Revista Argentina de Microbiología 49, 93-104. https://doi.org/10.1016/j. ram.2016.06.004
Ruess L, Lussenhop J. 2005. Trophic interactions of fungi and animals. In: Dighton J, White JF, Oudemans $P$ (eds.) The fungal community: its organization and role in the ecosystem. 3rd Edition. CRC Press, Taylor \& Francis, Boca Raton. 581-598.

Scheu S, Setäla H. 2002. Multitrophic interactions in decomposer communities. In: Tscharntke T, Hawkins BA (eds.) Multitrophic level interactions. Cambridge University Press, Cambridge. 223-264.

Schneider K, Renker C, Maraun M. 2005. Oribatid mite (Acari, Oribatida) feeding on ectomycorrhizal fungi. Mycorrhiza 16, 67-72. https://doi.org/10.1007/s00572-005-0015-8

Schneider K, Maraun M. 2005. Feeding preferences among dark pigmented fungal taxa ("Dematiacea") indicate limited trophic niche differentiation of oribatid mites (Oribatida, Acari). Pedobiologia 49, 61-67. https://doi.org/10.1016/j.pedobi.2004.07.010

Seastedt TR. 1984. The role of microarthropods in decomposition and mineralization processes. Annual Review of Entomology 29, 25-46. https://doi.org/10.1146/annurev.en. 29.010184.000325

Setälä H. 1995. Growth of birch and pine seedlings in relation to grazing by soil fauna on ectomycorrhizal fungi. Ecology 76, 18441851. https://doi.org/10.2307/1940716

Smith SE, Read DJ. 2008. Mycorrhizal Symbiosis. 3rd Edition. Academic Press, New York.

Starr C, Taggart R, Evers CA, Starr L. 2016. Which factors shape community structure? In: Wagner-Heuftle A (ed.) Biology: The unity and diversity of life. 14th Edition. Cengage Learning, Boston. 800.

Stebaeva SK. 1970. The life forms of springtails (Collembola). Zoologicheskii Zhurnal 49, 1437-1454.

Swift MJ, Heal OW, Anderson JM. 1979. Decomposition in terrestrial ecosystems. University of California Press, Berkeley.

Trocha LK, Oleksyn J, Turzanska E, Rudawska M, Reich PB. 2007. Living on the edge: ecology of an incipient Betula-fungal community growing on brick walls. Trees 21, 239-247. https://doi. org/10.1007/s00468-006-0116-9

Visser S, Whittaker JB. 1977. Feeding preferences for certain litter fungi by Onychiurus subtenuis (Collembola). Oikos 29, 320-325. https://doi.org/10.2307/3543621

Walter DE, Hunt HW, Elliott ET. 1988. Guilds or functional groups? An analysis of predatory arthropods from a shortgrass steppe soil. Pedobiologia 31, 247-260. 